\title{
PRODUÇÃO DO CONHECIMENTO E A PRÁTICA DA ENFERMAGEM: CONTEXTO POLÍTICO E SOCIAL
}

\author{
Gilmara Ribeiro Santos Rodrigues
}

Enfermeira. Doutora em Enfermagem. Docente na Universidade Federal da Bahia e na Escola Bahiana de Medicina e Saúde Pública. Editora científica na Revista Enfermagem Contemporânea.Salvador, Bahia, Brasil. gilmararodrigues@bahiana.edu.br

Globalmente estamos vivenciando uma transição planetária. No Brasil, a grande crise política e ética perpassa pelo desmonte das políticas sociais, do Sistema Único de Saúde (SUS) e da educação, principalmente das universidades públicas, que tem como resultado final a precarização dos serviços prestados às populações menos favorecidas.

Neste contexto, mediante uma liminar movida pelo Conselho Federal de Medicina que suspendeu temporariamente $\circ$ direito dos enfermeiros de requisitar exames complementares e realizar prescrição de medicamentos na atenção básica sem autorização médica, a Enfermagem se depara com um grande retrocesso por briga de poder e interesses mercadológicos de um grupo corporativista que preza por um sistema de saúde médico hegemônico que proporciona tratamento tecnicista, fragmentado e centrado apenas na doença, com sérios riscos à Política Nacional de Atenção Básica, além de ferir o direito do cidadão de ter acesso a prestação de cuidado integral e multiprofissional.

Uma outra vertente a ser considerada é a iniciativa por dissimular a expansão da categoria de Enfermagem que se destaca na prestação de um cuidado humanizado, centrado no indivíduo e baseado em evidências através da consulta e processo de enfermagem.

Com foco na atualização e na busca de conhecimento, os(as) enfermeiros(as) primam por se habilitarem, cursando além da formação acadêmica de cinco anos, uma média de dois anos de especialização e uma grande maioria, atualmente, também investe na formação stricto sensu. Neste processo de formação é intrínseco ao processo de capacitação, a produção do conhecimento.
A Revista Enfermagem Contemporânea com o intuito de corroborar a tríade prática-ensino-pesquisa vislumbra a análise crítica de questões sociais e o foco em novas tendências, contribuindo para a divulgação de conhecimento da área de Enfermagem. Nesta edição, refletimos sobre o processo de aproximação com outras áreas, em especial da saúde coletiva, com - intuito de proporcionar, ainda mais, a formação de novos pesquisadores, além de estimular e priorizar a publicação de produções científicas de qualidade de discentes de graduação e pós-graduação, oportunizando a aquisição de experiência em publicação científica. 